\title{
Siber Zorbalık Üçgeni Ölçeği: Geçerlilik ve Güvenirlik Çalışması
}

\author{
Cyber Bullying Triangle Scale: Validity and Reliability Study
}

\author{
Emine Zahide Özdemir, Murat Bektaş
}

Dokuz Eylül Üniversitesi Hemşirelik Fakültesi, Çocuk Sağlığı ve Hastalıkları Hemşireliği Anabilim Dalı

Yazı̧̧ma Adresi / Correspondence:

Emine Zahide Özdemir

Dokuz Eylül Üniversitesi Hemşirelik Fakültesi, Çocuk Sağlığı ve Hastalıkları Hemşireliği Anabilim Dalı, İnciralti, 35340/, İzmir, TURKIYE

T: +902324124791 E-mail : zahide.ozdemir@deu.edu.tr

Geliş Tarihi / Received : 09.11.2020 Kabul Tarihi / Accepte: 07.07.2021

Orcid :

Emine Zahide Özdemir https://orcid.org/0000-0002-4292-8849

Murat Bektaş https://orcid.org/0000-0003-3327-8204

( Sakarya Tip Dergisi / Sakarya Med J 2021, 11(3):583-592) DOI: 10.31832/smj.823355

\footnotetext{
$\ddot{\mathrm{O} z}$

Amaç Siber zorbalık, çevrimiçi iletișimin kullanımılla çocukların sağlığını olumsuz etkileme potansiyeli olan riskli bir durumdur. Bu ölçek siber zorba ve siber kurban olm durumlarını ölçmenin yanı sıra siber seyirci olma durumunu da ele almaktadır. Siber seyirci alt boyutunun ölçülebilmesinin, problemin kapsamlı bir șekilde tanımlanmasına katkı sağlayacağı düşünülmektedir. Bu çalışma, Siber Zorbalık Üçgeni Ölçeğı̉ni Türkçe’ye uyarlamak ve psikometrik özelliklerini incelemek amacıyla yapılmıștır.

Gereç ve Bu çalışma, tanımlayıcı, korelasyonel ve metodolojik desendedir. Nisan 2019-Eylül 2019 tarihleri arasında 9-17 yaş aralığındaki 1256 çocuk ile gerçekleștirilmiştir. Veri Yöntemler toplama așamasında sosyodemografik form ve Siber Zorbalık Üçgeni Ölçeği kullanılarak toplanmıștır. Açıklayıcı ve doğrulayıcı faktör analizleri, Cronbach alfa ve madde toplam puanı analiz edilmiștir

Bulgular Ölçek, 35 madde ve üç alt boyuttan oluşmaktadır. Üç alt ölçeğin, toplam varyansın \%35'ini açıkladığı bulunmuștur. Açıklayıcı Faktör yükleri birinci alt boyut için 0,41-0,66, ikinci alt boyut için 0,38-0,64 ve üçüncü alt boyut için 0,64-0,73 arasındadır. Ölçeğin toplamı için Cronbach alfa katsayısı 0,87, alt ölçekler için; siber kurban 0,66, siber zorba 0,80 ve siber seyirci için 0,87 'dir.

Sonuç Siber Zorbalık Üçgeni Ölçeği, Türk kültüründeki çocuk örneklemi için geçerli ve güvenilir psikometrik özellikleri göstermektedir. Bu ölçek, çocukların deneyimlerini üç boyutlu ele alarak kapsamlı bir șekilde değerlendirebilir. Koruyucu ve önleyici çalıșmalar için yön gösterici nitelikte olacağı düsünülmektedir.

Anahtar Siber zorba; Siber kurban; Siber seyirci; Cocuk.

Kelimeler

Abstract

Objective Cyberbullying is a risky situation that can negatively affect children's health through online communication. In addition to measuring cyberbully and cyber victim status, this scale also handles the cyber bystander status. It is thought that the cyber bystander sub-dimension measurement will contribute to the comprehensive definition of the problem. This study conducts to adopt the Cyber Bullying Triangle Scale to Turkish and examine its psychometric properties.

Materials and Methods

This study is descriptive, correlational, and methodological design. It conducts between April 2019 and September 2019 with 1256 children between 9 and 17. During the data collection phase, the sociodemographic form and Cyber Bullying Triangle Scale were used. Explanatory and confirmatory factor analyses, Cronbach alpha, and total item scores were analyzed

The scale consists of 35 items and three sub-dimensions. It found that three subscales explained 35\% of the total variance. Explanatory Factor loads are between $0.41-0.66$ for the first sub-dimension, 0.38-0.64 for the second sub-dimension, and 0.64-0.73 for the third sub-dimension. The Cronbach alpha coefficient for the scales total is 0.87 for the subscales, 0.66 for the cyber victim, 0.80 for the cyberbully, and 0.87 for the cyber bystander.

Conclusion Cyber Bullying Triangle Scale shows valid and reliable psychometric properties for the sample of children in Turkish culture. This scale can comprehensively evaluate children's experiences by considering them in three dimensions. It is thought to be a guide for preventive and protective interventions.

Keywords Cyberbully; Cyber victim; Cyber bystander; Child.
} 


\section{GIIRIŞ}

İnternet ortamında iletişim var olduğu sürece siber zorbalık yaşanması kaçınılmaz bir durumdur., ${ }^{1,2}$ Siber zorbalık, teknolojik araçlarla bir kişiye kasıtlı ve tekrarlayıcı biçimde zarar verme olarak tanımlanmaktadır. ${ }^{3,4}$ Zorbalığın farklı bir formu olan siber zorbalık olgusunda geleneksel zorbalığın aksine, sanal ortamın doğası gereği siber zorba/ zorbaların kim olduğu gizli kalabilmektedir. Siber mekandaki zorbalık, internet ortamındaki kişiler tarafından her zaman erişilebilir olabileceğinden zamandan ve mekandan bağımsız olarak kurbana zarar verebilmektedir. Bu özellikler göz önüne alındığında, siber zorbalık geleneksel zorbalıktan önemli ölçüde farklıdır. ${ }^{5,6}$

Güncel literatür incelendiğinde, tüm dünyada görülen siber zorbalığın çocuklar ve gençler arasında yaygın ve dikkate değer bir problem olduğu görülmektedir. Amerika Birleşik Devletleri’ndeki 2007 - 2019 yılları arasında ortaokul ve lise öğrencileri ile yapılan 11 çalışmanın incelendiği raporda öğrencilerin \%16'sı yaşamlarının bir döneminde siber zorbalık yaptığını, \%28'i ise siber kurban olduklarını ifade etmişlerdir.7 Amerika'da yapılan başka bir araştırma raporuna göre ise, 13-17 yaş arası gençlerin \%59’unun siber zorbalığ zorba veya kurban olarak deneyimlediklerini rapor etmişlerdir. ${ }^{8}$ Çin’de ortaokul öğrencileri ile yapılan güncel bir kesitsel çalışmada $(n=3774)$ öğrencilerin \%16,5'i siber zorba oldukların, \%31'i ise siber kurban olduklarını belirtmişlerdir. ${ }^{9}$ Türkiye örnekleminde ise, ergenlerin siber zorbalık deneyimlerini inceleyen geniş örneklemli bir çalışmada ( $\mathrm{n}=1129)$ ergenlerin \%65,5'inin siber kurban, \%56,6'sının siber zorba ve \%76,9'unun hem siber kurban hem siber zorba olduğu çarpıcı bir şekilde belirtilmiştir. ${ }^{10}$ Türkiyede ergenler ile yapılan bir başka çalışmada ise, siber kurban ve siber zorba yaygınlığının sırasıyla $\% 62,6$ ve $\% 53,3$ olduğu belirtilmiştir. ${ }^{11}$ Yapılan çalışmalar, siber zorbalığın günümüz toplumunda saldırganlığın yaygın bir biçimi olduğunu ve bu nedenle geçerli ve güvenilir ölçüm araçları ile problemi tanımlamanın önemli bir konu olduğunu göstermektedir.
Siber zorbalık ölçüm stratejilerini sistematik olarak inceleyen bir çalışmada siber zorbalığın ölçülme biçiminde terminolojik ve zamansal olarak tutarsızlıklar olduğu belirtilmektedir. ${ }^{12} \mathrm{Bu}$ tutarsız ölçüm biçimi ise araştırmacıların siber zorbalığın prevelans değerini oldukça farklı aralıklarda bulmalarına sebep olmaktadır. Siber zorbalık yapısının ölçülebilmesi ve siber zorbalığın önlenmesi için ölçüm araçlarının iyileştirilmesi gerektiği vurgulanmaktadır. ${ }^{12,13}$ Siber zorbalığı değerlendirmek için tasarlanan araştırmanın kriterlerine uyan mevcut 44 ölçüm aracının değerlendirildiği bir sistematik derlemede çoğu ölçüm aracının geçerlilik ve güvenirlik ile ilgili sınırlı bilgi içerdiği ifade edilmektedir. ${ }^{14}$

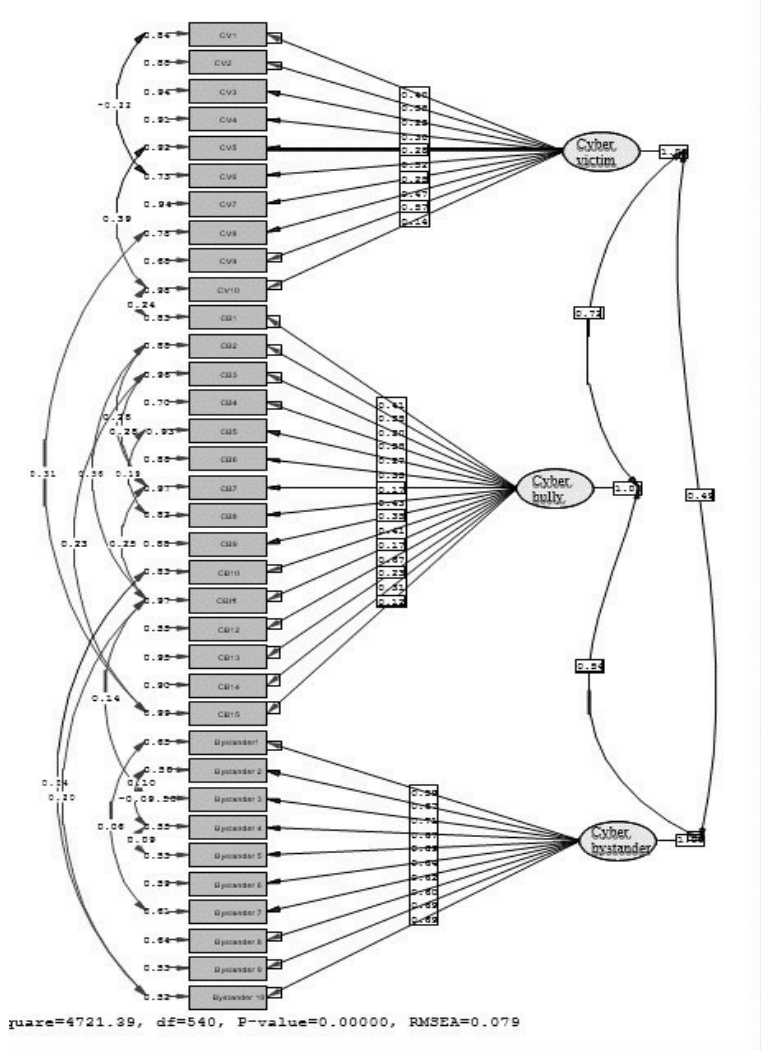

Şekil 1. Doğrulayıcı faktör analizi 
Siber zorbalı; siber zorba, siber kurban ve siber seyirci kavramlarından oluşmaktadır. Siber seyirci olan kişilerin siber zorbalığı önleme çalışmalarında önemli rollerinin olduğu vurgulanmaktadır. ${ }^{15,16}$ Türkiye örneklemi için çalışılan ölçekler incelendiğinde siber seyirci olma durumunu değerlendiren ölçüm aracına rastlanmamıştır. Bu çalışma siber zorbalık kavramını üç boyutlu olarak ele almasıyla diğer ölçeklerden farklı bir bakış açısı sunmaktadır. Ayrıca bu ölçek, siber zorba, siber kurban ve siber seyirci kavramları arasındaki ilişkinin tanımlanmasına da olanak sağlamaktadır. ${ }^{4,17,18}$ Siber seyirci alt boyutunun ölçülebilmesi hem problemin kapsamlı bir şekilde tanımlanmasına hem de önleyici programlar için yol gösterici olacağı düşünülmektedir.

\section{GEREÇ ve YÖNTEMLER}

$\mathrm{Bu}$ çalışma, tanımlayıcı, korelasyonel ve metodolojik olarak Siber Zorbalık Üçgeni Ölçeği'ni, Türkçe’ye uyarlamak ve psikometrik özelliklerini incelemek amacıyla yapılmıştır. Nisan 2019-Eylül 2019 tarihleri arasında Türkiye’nin batısında yer alan, sosyo ekonomik durumları orta düzey olan, rastgele seçilen iki ortaokul ve iki lise de Etik Kurul ve İl Milli Eğitim Müdürlüğü izinleri alındıktan sonra gerçekleştirilmiştir. Literatüre göre; geçerlik ve güvenirlik çalışmaları için iki ayrı örnekleme hesaplama tekniği önerilmektedir. İlk öneri; eğer örneklem sayısı yeterli ise madde başına 10-20 kişi alınmasıdır. Bu öneri baz alındığında çalışmaya en az 350 katılımcının alınması gerekmektedir. Diğer bir öneri ise; örneklem boyutu 100'e kadar yetersiz, 200'e kadar düşük seviye, 300-500’e kadar iyi, 500-1000 kadar çok iyi ve 1000 üstü mükemmel olarak değerlendirilmektedir. ${ }^{19} \mathrm{Bu}$ doğrultuda çalışmanın örneklem sayısının büyük olmasına araştırmacılar tarafından karar verilmiş ve mümkün olduğunca örneklemi 1000'in üzerine çıkarılması hedeflenmiştir. Bu doğrultuda, yaşları 9-17 arasında değişen, çalışmaya katılmayı gönüllü olarak kabul eden ve ebeveyn ve çocuk yazılı onam formlarını tam dolduran 1256 çocuk araştırma kapsamına alınmıştır.
Örnekleme alınma ölçütleri;

- Çocukların yaş aralığının 9-18 arasında olması

- Çocukların akıllı telefon/bilgisayar/tablet kullanmalar1

- Çocuk ve ebeveynden onam formunun alınması

\section{Araștırmanın Etik Yönü}

Siber Zorbalık Üçgeni Ölçeği için ölçeğini geliştiren sorumlu yazar Dr. Joaquin Gonzalez-Cabrera'dan e-mail aracılığıyla izin alınmıştır. Dokuz Eylül Üniversitesi Girişimsel Olmayan Klinik Araştırmalar Etik Kurulu'ndan etik kurul onayı alınmıştır (Tarih:10.04.2019 ve Karar No:2019/09-05). Daha sonra kurumsal izinler için İl Mili Eğitim Müdürlüğü’nden çalışmanın okullarda yapılabilmesi için izin alınmıştır. Ayrıca velilerinden ve çocuklardan yazılı onam alınmıştır. Bu araştırma Helsinki Bildirgesi ilkeleri ile uyumludur.

\section{Veri toplama Araçları}

Çalışmada veriler; "Sosyodemografik Veri Toplama Formu" ve "Siber Zorbalık Ölçeği” ile toplanmıştır. Ölçek formu ve bilgilendirmiş onam kapalı zarf ile velilere gönderilmiştir. Velisi bilgilendirmiş onamı doldurmuş olan öğrencilere açıklama yapılarak ölçek öğrencilere dağıtılmıştır. Gönüllü öğrenciler ölçek sorularını cavaplandırmıştır. Öğrencilerin anketi doldurma süresi ortalama 20 dakika sürmüştür.

Sosyodemografik Veri Toplama Formu: Çocuğa ilişkin yaş, cinsiyet, sınıf, kendilerine ait bilgisayarı olma durumu, kendilerine ait cep telefonu olma durumu gibi tanımlayıcı verilerin elde edilmesini sağlayan beş sorudan oluşmaktadır.

\section{Siber Zorbalık Üçgeni Ölçeği}

Gonzalez-Cabrera ve ark. (2019)20 tarafından siber zorbalık davranışlarını ölçmeye yönelik geliştirilmiştir. Ölçek, siber zorbalığın üç boyutunu ele alan 35 maddeden oluşur: Ölçek "siber kurban" on madde, "siber zorba" on beş madde, "siber seyirci" on madde olmak üzere üç alt 
boyuttan oluşmaktadır. Üç alternatif cevaplı $(0=$ asla, $1=$ ara sıra, 2 = sık sık) likert tipte ölçek puanlaması yapılmaktadır. Siber Zorbalık Üçgeni Ölçeği, tüm çocukların aynı anda üç rolün kombinasyonunu olabileceği varsayılarak, siber kurban, siber zorba veya siber seyirci perspektifinden açıklanan aynı 10 maddeye göre değerlendirilir. Siber zorba ölçeğinde diğer ölçeklerden farklı olarak eklenen beş madde vardır. Bu nedenle ölçeklerden alınan puanlar siber kurban ve siber seyirci alt boyutunda 0-20 arasinda değişirken siber-zorba alt boyutunda 0-30 arasında değişmektedir. Ölçeğin güvenirlik katsayıları ( $\alpha$ ) sırasıyla siber kurban, siber zorba ve siber seyirci alt boyutlarının 0,94, 0,96 ve 0,95 'tir. Doğrulayıcı faktör analizi sonucuna göre $\mathrm{S}-\mathrm{B} \chi 2(526, \mathrm{n}=5036)=1180, \mathrm{p}<0,001 ; \mathrm{RMSEA}=0,016$ (\%95 CI: 0,015-0,017); CFI =0,999; NNFI =0,999. SRMR $=0,059$.

Araştırmanın başında ölçek geliştiricilerinin yazılı onayı alınmıştır. Ölçek iki dil uzmanı tarafından İngilizce'den Türkçe’ye çevrilmiştir. Araştırmacılar, iki çeviriyi inceledikten sonra ölçeği daha önce görmemiş olan bir dil uzmanına göndermiş ve tekrar İngilizce'ye çevrilmiştir. Araştırmacılar bu çeviriler doğrultusunda Türkçe formun son halini elde etmiştir. Dil uzmanları ölçeğin son halini değerlendirmişlerdir.

Literatürde ölçeğin geçerliliğinin en az üç uzman tarafından değerlendirilmesi gerektiği belirtilmektedir. Pediatri Hemşireliği Bölümü’nden dört öğretim elemanı, iki psikolog ve Psikiyatri Bölümünden iki akademisyen olmak üzere toplam sekiz uzman ölçeği değerlendirmiştir. Ölçeğin taslak formu ve İngilizce orijinal versiyonu uzmanlara verilerek maddelerin uygunluğunu ( $1=$ hiç uygun değil, 4 = tamamen uygun) puanlamışlardır. Uzman puanları content validity index (CVI) 'ine göre değerlendirilmiştir. Uzman görüşlerine göre ölçeğin taslak formu yeniden düzenlenmiştir.

Çalışma deneklerine benzer özelliklere sahip fakat çalışma örneklemine dahil olmayan 35 çocuğa uygulanmıştır.
Olumsuz/geliştirilmesi gereken bir geri bildirim alınmadığından çalışmaya devam edilmiştir. Pilot çalışmaya katılan öğrenciler örneklem dışı bırakılmıştır.

\section{Verilerin Değerlendirilmesi}

Verilerin analizinde IBM SPSS Statistics 21.0 ve LISREL 8.8 paketleri kullanılmıştır. Tanımlayıcı istatistikler için sayı, yüzde ve ortalama alınmıştır. Geçerliliğin belirlenebilmesi için kapsam geçerlilik indeksi (CVI) hesaplandı. Madde-faktör ilişkisinin belirlenmesi için açıklayıcı faktör analizi (AFA) yapılmıştır. Maddelerin ve alt boyutların ölçeğin özgün yapısını açıklama durumunu değerlendirmek için doğrulayıcı faktör analizi (DFA) hesaplandı. Bir maddenin bir faktör altında yer alabilmesi için faktör yükünün 0,30'dan büyük olması ve diğer faktörler altındaki yüklerden 0,10 puan yüksek olması baz alınmıştır. Kaiser - Meyer - Olkin (KMO) testi, Bartlett'in küresellik testi, Root Mean Square Error of Approximation (RMSEA), Degrees of Freedom, Comprarative Fit Index (CFI), Goodness of Fit Index (GFI) değerleri analiz edilmiştir. Ölçeğin güvenirliğinin belirlenmesi için Cronbach Alfa katsayısı kullanılmıştır. Madde-toplam puan analizleri yapılmış ve iki yarıya bölme analizi kullanılmıştır. Tepki yanlılığını belirlemek için ise Hotelling’s T-kare testi yapılmıştır. Verilerin değerlendirilmesinde hata payı $\mathrm{p}=0,05$ olarak alınmıştır.

\section{BULGULAR}

Çalışmaya katılan çocuk ve ergenlerin yaş ortalaması 14,75 $\pm 3,11$ idi. Çocukların \%53,7’si $(\mathrm{n}=674) \mathrm{k}$, $\% 91,5$ 'i cep telefonundan internete bağlanmakta ve \%67,2'sinin kendisine ait bilgisayarı bulunmaktadır.

\section{İçerik Geçerliliği}

Sekiz uzman görüşü içerik geçerlilik analizi ile değerlendirilmiştir. Ölçek içerik geçerlilik indeksi (S-CVI) 0,95’tir. Madde-içerik geçerlik indeksi ise (I-CVI) 0,87-0,99 arasında değişmektedir.

\section{Yapı Geçerliliği}

Yapılan faktör analizinde KMO katsayısı 0,887, Bartlett's 
test X2 değeri 12508,745 bulunmuştur $(\mathrm{p}<0,01)$. Ölçeğin toplam üç alt boyutu vardır: birinci alt boyut (siber kurban) toplam varyansin $\% 15,08$ 'ini, ikinci alt boyut $\% 12,31$ 'ini ve üçüncü alt boyut \%7,83'ünü oluşturmuştur. Ölçeğin toplam varyansı \%35,23’tür.

\section{Açılayıcı (AFA) ve Doğrulayıcı Faktör Analizi (DFA)}

Açıklayıcı Faktör analizinde faktör yükleri birinci alt boyut için 0,41-0,66, ikinci alt boyut için 0,38-0,64 ve üçüncü alt boyut için 0,64-0,73’tür (Tablo 1). Doğrulayıcı faktör analizinde Uyum indeksi sonuçları RMSEA $=0,079$, GFI $=0,82, \mathrm{CFI}=0,83, \mathrm{IFI}=0,83, \mathrm{RFI}=0,80, \mathrm{NFI}=0,82$ ve NNFI $=0,82$ bulunmuştur (Tablo 2). Hotelling's T-kare değeri $3073,518, F=87,982$ ve $p<0,01$ 'dir. Ölçekte tepki yanlılı̆̆ı bulunmamıştır.

\section{Güvenirlik Analizleri}

Siber Zorbalık Üçgeni Ölçeği’nin Türkçe versiyonunun güvenilirlik katsayısı (35 Madde) $\alpha=0,87$ olarak bulunmuştur. Siber kurban alt boyutu (10 Madde) $\alpha=0,66$, siber zorba alt boyutu ( 15 Madde) $\alpha=0,80$, Siber seyirci alt boyutu (10 Madde) $\alpha=0,87$ 'dir. Ölçek iki yarıya bölme analizi sonucunda birinci yarının cronbach alfa değeri 0,81 ve ikinci yarının cronbach alfa değeri 0,73 olarak saptanmıştır. Spearman-Brown katsayısı 0,86, Guttman’n bölünmüss yarı katsayısı 0,86 ve korelasyon katsayısı iki yarım 0,76 bulunmuştur (Tablo 3). Madde ölçeği toplam puan korelasyonu 0,20-0,57, madde-alt ölçek toplam puanı 0,21-0,59 bulunmuştur (Tablo 4).

\begin{tabular}{|l|c|c|c|}
\hline \multirow{2}{*}{ Tablo 1. Açıklayıcı Faktör Analizi $(\mathrm{n}=1256)$} \\
\cline { 2 - 4 } & \multicolumn{3}{|c|}{ Alt Boyutlar } \\
\hline 1 & Siber Kurban & Siber Zorba & Siber Seyirci \\
\hline 2 &, 418 &, 380 &, 648 \\
\hline 3 &, 233 &, 519 &, 726 \\
\hline 4 &, 418 &, 550 &, 734 \\
\hline 5 &, 528 &, 510 &, 714 \\
\hline 6 &, 532 &, 532 &, 703 \\
\hline 7 &, 458 &, 398 &, 656 \\
\hline 8 &, 529 &, 497 &, 678 \\
\hline 9 &, 423 &, 538 &, 670 \\
\hline 10 &, 663 &, 520 &, 663 \\
\hline 11 &, 444 &, 640 &, 720 \\
\hline 12 & &, 485 & \\
\hline 13 & &, 465 & \\
\hline 14 & &, 400 & \\
\hline 15 & &, 599 & \\
\hline Açılanan varyans (\%) & 15.08 & 12.31 & \\
\hline
\end{tabular}

Tablo 2. Model Uyum İndeksleri

\begin{tabular}{|c|c|c|c|c|c|c|c|c|c|c|}
\hline & $\mathrm{X}^{2}$ & $\mathrm{DF}^{\mathrm{a}}$ & $\mathrm{X}^{2} / \mathrm{DF}$ & RMSEA $^{\mathrm{b}}$ & GFI $^{\mathrm{c}}$ & CFI $^{\mathrm{d}}$ & IFI $^{\mathrm{e}}$ & RFI $^{\mathrm{f}}$ & NFI $^{\mathrm{g}}$ & NNFI $^{\mathrm{h}}$ \\
\hline Üç faktörlü model & 4839.33 & 540 & 459.92 & 0.079 & 0.82 & 0.83 & 0.83 & 0.80 & 0.82 & 0.82 \\
\hline
\end{tabular}

Note: a: Degree of freedom; b: Root mean square error of approximation; c: Goodness of fit index; d: Comparative fit index; e: Incremental fit index; f: Relative fit index; g: Normed fit index; h: Non- Normed fit index 


\begin{tabular}{|l|c|c|c|c|c|c|c|}
\hline Table 3. Ölçek ve Alt Boyutların Güvenilirlik Analizi (n=1256) \\
\hline Alt Boyutlar & Cronbach $\alpha$ & $\begin{array}{c}\text { Birinci Yarı } \\
\text { Cronbach } \alpha\end{array}$ & $\begin{array}{c}\text { İkinci Yarı } \\
\text { Cronbach } \alpha\end{array}$ & $\begin{array}{c}\text { Spearman- } \\
\text { Brown }\end{array}$ & $\begin{array}{c}\text { Guttman split- } \\
\text { half }\end{array}$ & $\begin{array}{c}\text { İki Yarı } \\
\text { Arasındaki } \\
\text { Korelasyon }\end{array}$ & M \pm SD \\
\hline Toplam Ölçek & 0.87 & 0.81 & 0.73 & 0.86 & 0.86 & 0.76 & $44,38 \pm 7,53$ \\
\hline Siber Kurban & 0.66 & & & & & & \\
\hline Siber Zorba & 0.80 & & & & & & $12,07 \pm 2,01$ \\
\hline Siber Seyirci & 0.87 & & & & & $17,03 \pm 3,11$ \\
\hline
\end{tabular}

\begin{tabular}{|c|c|c|c|}
\hline Maddeler & $\mathrm{X} \pm \mathrm{SS}$ & $\begin{array}{l}\text { Madde-toplam puan } \\
\text { korelasyonu }(\mathrm{r})^{*}\end{array}$ & $\begin{array}{l}\text { Madde-alt ölçek toplam } \\
\text { puan korelasyonu }(\mathrm{r})^{*}\end{array}$ \\
\hline \multicolumn{4}{|l|}{ Siber Mağduriyet } \\
\hline $\begin{array}{l}\text { 1. Cep telefonundan tehdit veya hakaret içeren mesajlar almam (Whatsapp, Instagram, } \\
\text { Twitter...) }\end{array}$ & $1,2682 \pm, 46374$ & ,361 & ,330 \\
\hline 2. İnternette aşağılayıcı resimlerimin paylaşılması & $1,7614 \pm, 55146$ & ,305 & 219 \\
\hline $\begin{array}{l}\text { 3. İnternette benimle ilgili utanç verici şakalar, dedikodular, dedikodular veya yorumlar } \\
\text { yazılması }\end{array}$ & $1,1532 \pm, 39778$ & ,265 & 319 \\
\hline $\begin{array}{l}\text { 4. E-posta veya sosyal ağlar aracıllığıyla beni zor durumda bırakacak mesajlar gönder- } \\
\text { mek için hesabımın hacklenmesi }\end{array}$ & $1,1038 \pm, 34631$ & ,208 & 323 \\
\hline $\begin{array}{l}\text { 5. Beni küçük düşürücü veya gülünç bir şey yapmaya zorlarken cep telefonuyla video- } \\
\text { mun kaydedilmesi veya fotoğrafımın çekilmesi }\end{array}$ & $1,0990 \pm, 34771$ & 246 & ,332 \\
\hline $\begin{array}{l}\text { 6. Biri bana vururken veya canımı acıtırken cep telefonuyla videomun kaydedilmesi } \\
\text { veya fotoğrafımın çekilmesi }\end{array}$ & $1,2011 \pm, 44571$ & ,307 & ,353 \\
\hline 7. İnternette benimle ilgili küçük düşürücü bilgi, görüntü ve sırlarımın yayılması & $1,0918 \pm, 31236$ & 254 & 347 \\
\hline 8. Kasıtlı olarak çevrimiçi bir gruptan dışlanmam & $1,2051 \pm, 46236$ & ,302 & ,349 \\
\hline 9. Tehdit içeren veya çok korkutucu mesajları tekrar tekrar almam & $1,1269 \pm, 37748$ & ,374 & ,492 \\
\hline $\begin{array}{l}\text { 10. Uygunsuz bir tür davranışta bulunurken videoya kaydedilmem veya cep telefonuyla } \\
\text { resimlerimin çekilmesi }\end{array}$ & $1,0615 \pm, 25290$ & ,266 & ,309 \\
\hline \multicolumn{4}{|l|}{ Siber Zorbalık } \\
\hline $\begin{array}{l}\text { 1. Cep telefonundan tehdit veya hakaret içeren mesajlar göndermek (Whatsapp, Insta- } \\
\text { gram, Twitter...) }\end{array}$ & $1,1872 \pm, 43566$ & ,422 & ,406 \\
\hline 2. Bir arkadaşının küçük düşürücü görüntülerini internette paylaşmak & $1,0833 \pm, 29246$ & ,353 & ,444 \\
\hline 3. Başkalarının görmesi için aşağılayıcı resimler içeren bağlantılar yayınlamak & $1,1120 \pm, 66818$ & ,304 &, 373 \\
\hline $\begin{array}{l}\text { 4. Arkadaşın hakkında internete utanç verici şakalar, söylentiler, dedikodular veya } \\
\text { yorumlar yazmak }\end{array}$ & $1,1008 \pm, 34721$ & ,406 & ,479 \\
\hline $\begin{array}{l}\text { 5. Arkadaşının veya bir tanıdığının okuması için diğer insanlara söylentiler, dedikodu- } \\
\text { lar vb. içeren bağlantılar göndermek }\end{array}$ & $1,1912 \pm, 42931$ & ,321 & ,437 \\
\hline $\begin{array}{l}\text { 6. E-posta veya sosyal ağlar aracılığıyla karşıdaki kişiye sorun çıkarabilecek mesajlar } \\
\text { göndermek için hacklemek }\end{array}$ & $1,0840 \pm, 31959$ & ,295 & ,355 \\
\hline $\begin{array}{l}\text { 7. Bir başkasını küçük düşürücü veya gülünç bir şey yapmaya zorlarken video kaydet- } \\
\text { mek veya cep telefonuyla fotoğraf çekmek }\end{array}$ & $1,0480 \pm, 23126$ & ,302 & ,429 \\
\hline $\begin{array}{l}\text { 8. Başkalarının görmesi için izinsiz çekilen rahatsız edici görüntüleri internette paylaş- } \\
\text { mak }\end{array}$ & $1,2072 \pm, 46669$ & 411 & ,480 \\
\hline $\begin{array}{l}\text { 9. Birisi başka birine vururken veya zarar verirken cep telefonuyla video veya fotoğraf } \\
\text { çekmek }\end{array}$ & $1,1624 \pm, 41104$ & ,358 & 417 \\
\hline 10. Kaydedilen kavga görüntülerini başka kişilerle paylaşmak & $1,2366 \pm, 47336$ & ,378 & ,496 \\
\hline 11. İnternette başkalarının sırlarını, bilgi veya görüntüleri yaymak & $1,0673 \pm, 28277$ & ,347 & 441 \\
\hline 12. Birini çevrimiçi bir gruptan kasten dışlamak & $1,2363 \pm, 47446$ & 445 & 447 \\
\hline 13. Tehdit içeren veya çok korkutucu mesajları tekrar tekrar göndermek & $1,0689 \pm, 27955$ & 292 & 359 \\
\hline
\end{tabular}


Sakarya Tip Dergisi 2021;11(3):583-592

ÖZDEMIR ve Ark., Siberzorbalık Üçgeni Ölçeği

\begin{tabular}{|c|c|c|c|}
\hline 14. Bir arkadaşını uygunsuz bir tür davranış sergilerken video veya fotoğraf çekmek & $1,1337 \pm, 36442$ &, 367 & ,439 \\
\hline 15. Arkadaşının uygunsuz görüntülerini başka kişilere göndermek & $1,1201 \pm, 35028$ & ,345 & ,421 \\
\hline \multicolumn{4}{|l|}{ Siber Seyirci } \\
\hline $\begin{array}{l}\text { 1. Cep telefonundan (Whatsapp, Instagram, Twitter vb.) tehdit veya hakaret içeren } \\
\text { mesajlar gönderildiğini görmek }\end{array}$ & $1,6598 \pm, 66183$ &, 559 &, 576 \\
\hline 2. İnternette birinin başka bir kişinin aşağılayıcı resimlerini paylaștığını görmek & $1,6637 \pm, 61851$ &, 572 & 642 \\
\hline $\begin{array}{l}\text { 3. Bir arkadaşını utandırmak için internette şakalar, söylentiler ve dedikodular yayan } \\
\text { birini görmek }\end{array}$ & $1,6311 \pm, 61985$ &, 566 & 660 \\
\hline $\begin{array}{l}\text { 4. E-posta veya sosyal ağlar aracıllı̆ıyla birini zor durumda bırakacak mesajlar gönder- } \\
\text { mek için hesabının hacklendiğini görmek }\end{array}$ & $1,3833 \pm, 56219$ &, 590 & ,658 \\
\hline $\begin{array}{l}\text { 5. Birini küçük düșürücü veya gülünç bir şey yapmaya zorlarken cep telefonuyla video- } \\
\text { sunun veya fotoğrafının çekildiğini görmek }\end{array}$ & $1,4286 \pm, 58457$ &, 552 & ,634 \\
\hline $\begin{array}{l}\text { 6. Birinin başka birine vurduğu veya yaraladığı sırada cep telefonuyla video veya } \\
\text { fotoğraf çektiğini görmek }\end{array}$ & $1,4574 \pm, 58088$ & ,493 &, 579 \\
\hline 7. Birinin başka bir kişiye ait bilgileri, görüntüleri ve sırları internette yaydığını görmek & $1,5147 \pm, 60639$ &, 556 & 615 \\
\hline 8. Birinin çevrimiçi bir gruptan kasten dışladığını görmek & $1,7044 \pm 1,02996$ & ,358 & ,465 \\
\hline $\begin{array}{l}\text { 9. Birinin başka bir kişiye tekrar tekrar tehdit içeren veya çok korkutucu mesajlar } \\
\text { gönderdiğini görmek }\end{array}$ & $1,3649 \pm, 57909$ &, 587 & ,617 \\
\hline 10. Uygunsuz davranan birini başka birinin video veya fotoğraf çektiğini görmek & $1,4661 \pm, 59232$ &, 572 & ,654 \\
\hline
\end{tabular}

\section{TARTIŞMA}

Ölçek içerik geçerlilik indeksi (S-CVI) 0,95’tir. Madde-içerik geçerlik indeksi ise (I-CVI) 0,87-0,99 arasında değişmektedir. Literatürde bu oranların 0,80'in üzerinde olması gerektiği vurgulanmaktadır. ${ }^{21,22} \mathrm{Bu}$ çalışmadaki sonuçlar uzmanların ölçeğin içeriğine yönelik fikir birliğine vardığını göstermiştir.

Bartlett küresellik testi ve KMO değerleri testi kullanılarak verilerin ve örneklem büyüklüğünün faktör analizi için yeterliliği değerlendirilmiştir. Bartlett küresellik testi değerinin istatistiksel olarak anlamlı olması ve KMO değerinin 0,60'dan yüksek olması beklenir. ${ }^{22-24} \mathrm{Bu}$ çalışmadaki AFA, KMO ve Bartlett's testlerinin gerekli koşulları sağladığı, örneklem sayısının ve verilerin faktör analizi için uygun olduğu saptanmıştır. ${ }^{22-24} \mathrm{Bu}$ çalışmada ölçeğin orijinal yapısının korunması için AFA ve DFA üç alt boyut olacak şekilde analizler yapılmıştır. AFA sonucunda, üç faktörlü yapının toplam varyansın \%35,23'ünü açıkladığı belirlenmiştir. Türk örnekleminde üç alt boyutun açıkladığı varyansın orijinal ölçekte açıklanan varyanstan düşük olduğu belirlenmiştir. Bu çalışmadaki AFA faktör yükleri 0,410,73 arasındadır (Table 1). Orijinal ölçekte ise 0,38-0,67 arasında değişmektedir. Orijinal ölçek ile bu çalışma faktör yükleri benzerlik göstermektedir. Her alt boyuttan ölçülen faktör yüklerinin 0,30 'dan fazla değerde olması güçlü bir faktör yapısında olduğunu göstermektedir. Literatüre göre faktör yüklerinin en az 0,30 olması bu değerin altındaki maddelerin çıkarılması önerilmektedir. ${ }^{22-25} \mathrm{Bu}$ analiz sonuçları AFA faktör yüklerinin istenen düzeyde olduğunu göstermiştir.

DFA analizi sonuçlarına göre, uyum indeksi sonuçları, RMSEA <0,080 ve GFI, CFI, IFI, RFI, NFI, NNFI değerleri $>0,80$ bulunmuştur. Bu değerler ölçeğin ve ölçeğin alt boyutlarının arasında anlamlı bir ilişki olduğunu göstermektedir. DFA sonuçlarına göre, verilerin modelle uyumlu olduğu, üç alt boyutlu yapının doğrulandığı ve alt boyutların ölçekle ilişkili olduğu bulunmuştur. ${ }^{19,26}$ DFA faktör yüklerinde ise 0,30'un altında kalan maddeler olmuştur. Fakat bu maddelerin önemli olmaları, ölçeğin yapısının bozulmaması amacıyla ölçekten çıkarılmamasına karar verilmiştir. Faktör analizi sonuçları ölçeğin yapı geçerliliğini desteklemiştir.

Cronbach alfa katsayısı, ölçekteki maddeler arasındaki or- 
talama korelasyonu ölçer. Bu değerin 1'e yakın olması beklenmektedir. ${ }^{27-29} \mathrm{Bu}$ çalışmada total ölçeğin ve alt boyutlarının cronbach alfa katsayısı >0,70'tir. Bu bulgu, ölçeğin ve alt boyutlarının güvenilir olduğunu göstermektedir. Maddelerin ilgili konuyu ölçmede yeterli olduğu ve ölçeğin iyi bir güvenirliğe sahip olduğu bulunmuştur. Orijinal ölçekte güvenirlik katsayısı >0,94 bulunmuştur. Güvenirlik katsayısı sonuçları orijinal ölçek ve bu çalışma arasında uyumlu bulunmuştur.

Güvenirlik analizlerin yapılması önerilen diğer bir test ise iki yaraya bölme analizidir. İki yarıya bölme analizi sonucunda her iki yarının >0,70 olduğu bulunmuştur. Spearman-Brown ve Guttman'ın split-half katsayıları incelendiğinde $>0,70$ olduğu, iki yarı arasında güçlü bir ilişki olduğu saptanmıştır. Bu bulgular, ölçeğin iç geçerliliğinin yüksek olduğunu göstermektedir. Orijinal ölçekte iki yarıya bölme analizleri yapılmadığından sonuçlar karşılaştırılamamıştır.

Yanıt yanlılığı ölçeğin güvenirliğini etkileyen önemli bir konudur. Yanıt yanlılı̆̆ı, ölçeği dolduran katılımcıların, araştırmacının ya da toplumun beklentilerine göre cevap verme durumunu ifade etmektedir. Ölçek sorularının beklentilere göre cevaplandırılması hem güvenirliği hem de geçerliliği etkiler. Yanıt yanlılığını olma durumunu belirlemek için Hotelling's T-kare testi yapılmıştır. ${ }^{30,31}$ Bu test sonucunda çocukların kendi görüşlerine göre yanıt verdikleri, katılımcıların yanıtlarının birbirinden farklı olduğu ve yanıt yanlılığı olmadığı bulunmuştur. Dolayısıyla ölçeğin güvenilir olduğu gösterilmiştir. ${ }^{28-30}$

Her bir maddenin beklenen düzeyde ölçüm yapabildiğini göstermek için her bir maddenin puanı ile ölçeğin toplam puanı arasındaki ilişki açıklayan madde toplam puan analizi yapılmıştır. Bu değerin $>0,20$ olması beklenmektedir. ${ }^{22-25}$ Ölçeğin toplam puan korelasyonu 0,20-0,57, madde-alt ölçek toplam puanı 0,21-0,59 bulunmuştur. Bu sonuçlar, ölçeğin alt boyutlarının toplam puan ile korelasyonu olduğunu ve madde güvenilir olduğu göstermektedir. Orijinal ölçekte toplam puan analizi yapılmadığından sonuçlar karşılaştırılamamıştır.

Sonuç olarak, Türk çocuklarını içeren örneklem ile orijinal ölçeğin özellikleri benzerlik göstermektedir. Ölçeğin, Türk kültürü için psikometrik açıdan uygun geçerli ve güvenilir ölçüm aracı olduğu sonucuna varılmıştır.

Çocukların sağlığının korunması ve buna yönelik önleyici çalışmaların yapılabilmesi için internet ortamındaki zorbalık davranışını kapsamlı bir şekilde değerlendiren geçerli ve güvenilir ölçeklere gereksinim duyulmaktadır. Bu çalışma, siber zorba - kurban - seyirci rollerini kapsamlı bir şekilde ele almaktadır ve orijinal ölçekle uyumlu bulunmuştur. Bu ölçeği, çocuk sağllğ hekimleri ve hemşireleri, halk sağlığ hekimleri ve hemşireleri, psikiyatri hekimleri ve hemşireleri, çocuk gelişimi uzmanları, eğitimciler ve çocuk sağlığını geliştirmeye yönelik çalışan tüm meslek grupları kullanarak çocukların internet ortamındaki siber zorbalık rollerini değerlendirebilir. Siber zorbalı̆̆ı önlemeye yönelik yapılan girişimlerin etkinliğini değerlendirmeye yönelik kullanılabilir. Farklı kültürlerdeki çocukların internet ortamındaki siber zorbalık rollerinin karşılaştırılması için de kullanılabilir.

\section{Çalışmanın Kısıtlılı̆̆ı}

Bu çalışma gelişigüzel örneklemin kullanılması bir sınırlılıktır. Çalışmaya sadece gönüllü çocuklar ve ebeveyn izni olan çocuklar dahil edilmiştir. Bu durum ölçeğin genellenebilir olma durumunu etkileyebilir.

\section{Çıkar Çatışması}

Yazarların çıkar çatışması yoktur.

\section{Etik onay}

Dokuz Eylül Üniversitesi Girişimsel Olmayan Klinik Araştırmalar Etik Kurulu'ndan (Tarih:10.04.2019 ve Karar No:2019/09-05) etik kurul onayı alınmıștır. Daha sonra kurumsal izinler için T.C. İzmir Valiliği İl Mili Eğitim Müdürlüğü’nden (Sayı:12018877-604.01. 02-E.22375365) okulda çalışmanın yapılabilmesi için 
izin alındı. Ayrıca velilerinden ve çocuklardan onam alınmıştır. Bu araştırma Helsinki Bildirgesi ilkeleri ile uyumludur.

\section{Teșekkür}

Çalışmaya katılarak bilimsel bilgi üretime destek veren tüm çocuklara ve onların ailelerine teşekkür ediyoruz. 


\section{Sakarya Tip Dergisi 2021;11(3):583-592}

ÖZDEMİR ve Ark., Siberzorbalı Üçgeni Ölçeği

\section{Kaynaklar}

1. Barlett CP. From theory to practice: Cyberbullying theory and its application to intervention. Comput Human Behav. 2017;72:269-275. doi:10.1016/j.chb.2017.02.060

2. Barlett CP, Heath JB, Madison CS, DeWitt CC, Kirkpatrick SM. You're Not Anonymous Online: The Development and Validation of a New Cyberbullying Intervention Curriculum. Psychol Pop Media Cult. Published online 2019. doi:10.1037/ppm0000226

3. Hinduja S, Patchin JW. Cultivating youth resilience to prevent bullying and cyberbullying victimization. Child Abus Negl. 2017;73:51-62. doi:10.1016/j.chiabu.2017.09.010

4. Özbey H, Başdas Ö. Psychometric properties of the Turkish version of the Bullying and $C y$ ber Bullying Scale for Adolescents (BCS-A). Psychiatry Res. 2020;289:112994. doi:10.1016/j. psychres.2020.112994

5. Ansary NS. Cyberbullying: Concepts, theories, and correlates informing evidence-based best practices for prevention. Aggress Violent Behav. 2020;50:101343. doi:10.1016/j. avb.2019.101343

6. Çelik S, Atak H, Erguzen A. The Effect of Personality on Cyberbullying among University Students in Turkey. Eurasian J Educ Res. 2012;49:129-150.

7. Patchin J, Hinduja S. Summary of Our Cyberbullying Research (2007-2019). Cyberbullying Research Center. Published June 10, 2019. Accessed May 3, 2020. https://cyberbullying.org/ summary-of-our-cyberbullying-research

8. Anderson M, Smith A, Nolan H. A Majority of Teens Have Experienced Some Form of Cyberbullying. 2018; 27 (2):67-66.

9. Li J, Sidibe AM, Shen X, Hesketh T. Incidence, risk factors and psychosomatic symptoms for traditional bullying and cyberbullying in Chinese adolescents. Child Youth Serv Rev. 2019;107. doi:10.1016/j.childyouth.2019.104511

10. Uludasdemir D, Kucuk S. Cyber Bullying Experiences of Adolescents and Parental Awareness: Turkish Example. J Pediatr Nurs. 2019;44:84-90. doi:10.1016/j.pedn.2018.11.006

11. Gül H, Firat S, Sertçelik M, Gül A, Gürel Y, Kilıç BG. Cyberbullying among a clinical adolescent sample in Turkey: effects of problematic smartphone use, psychiatric symptoms, and emotion regulation difficulties. Psychiatry Clin Psychopharmacol. 2018;1-11. doi:10.1080/ 24750573.2018.1472923

12. Vivolo-Kantor AM, Martell BN, Holland KM, Westby R. A systematic review and content analysis of bullying and cyber-bullying measurement strategies. Aggress Violent Behav. 2014;19(4):423-434. doi:10.1016/j.avb.2014.06.008

13. Zych I, Ortega-Ruiz R, Marín-López I. Cyberbullying: A systematic review of research, its prevalence and assessment issues in Spanish studies. Psicol Educ. 2016;22(1):5-18. doi:10.1016/j.pse.2016.03.002

14. Berne S, Frisén A, Schultze-Krumbholz A, et al. Cyberbullying assessment instruments: A systematic review. Aggress Violent Behav. 2013;18(2):320-334. doi:10.1016/j. avb.2012.11.022

15. Bauman S, Yoon J, Iurino C, Hackett L. Experiences of adolescent witnesses to peer victimization: The bystander effect. J Sch Psychol. 2020;80:1-14. doi:10.1016/j.jsp.2020.03.002

16. Doane AN, Ehlke S, Kelley ML. Bystanders Against Cyberbullying: a Video Program for College Students. Int J Bullying Prev. Published online 2019. doi:10.1007/s42380-019-00051-5
17. Çetin B, Yaman E, Peker A. Cyber victim and bullying scale: A study of validity and reliability. Comput Educ. 2011;57(4):2261-2271. doi:10.1016/j.compedu.2011.06.014

18. Gençdoğan B, Cikrikci O. Reliability and Validity Studies of the Turkish Version of the E-Bullying Scale (E-BS) and E-Victimization Scale (E-VS) The Effect of Internet Use on Well-Being View Project Determinants of Life Satisfaction View Project.; 2015;11(1)359373.

19. Șimșek Ö. Yapisal Eșitlik Modellemesine Giriș: Temel Ilkeler ve LISREL Uygulamalari. 2020;46-98.

20. González-Cabrera JM, León-Mejía A, Machimbarrena JM, Balea A, Calvete E. Psychometric properties of the cyberbullying triangulation questionnaire: A prevalence analysis through seven roles. Scand J Psychol. 2019;60(2):160-168. doi:10.1111/sjop.12518

21. Polit DF, Beck CT, Owen S V. Focus on research methods: Is the CVI an acceptable indicator of content validity? Appraisal and recommendations. Res Nurs Heal. 2007;30(4):459-467. doi:10.1002/nur.20199

22. Terwee $C$, Bot $S$, Boer MR, et al. Quality criteria were proposed for measurement properties of health status questionnaires. J Clin Epidemiol. 2007;60(1):34-42. doi:10.1016/J.JCLINEPI.2006.03.012

23. DeVellis R. Scale Development: Theory and Applications. 3rd ed. Sage Publisher; 2012.

24. Hayran M, Hayran M. Basic Istatistics for Health Surveys. 1st. edition. Art Ofset Publication; 2011.

25. Johnson B, Christensen L. Educational Research: Quantitative, Qualitative, and Mixed Approaches. 3rd ed. Sage Publication; 2007.

26. Hooper D, Coughlan J, Mullen M. Structural Equation Modelling: Guidelines for Determining Model Fit. Electron J Bus Res Methods. 2008;6(1):53-60.

27. Çam M, Baysan-Arabacı L. Qualitative and quantitative steps on attitude scale construction. Hemar-G 2010;59-71.

28. Rattray J, Jones MC. Essential elements of questionnaire design and development. J Clin Nurs. 2007;16(2):234-243. doi:10.1111/j.1365-2702.2006.01573.x

29. Sencan H. Validity and Reliability in Social and Behavioral Measurements. Ist edition. Seckin Publishing; 2005.

30. Krueger BI, Storkel HL. Children's Response Bias and Identification of Misarticulated Words. J Speech, Lang Hear Res. 2019;63(1):259-273. doi:10.1044/2019_JSLHR-19-00140

31. Paulhus DL. Measurement and Control of Response Bias. In: Measures of Personality and Social Psychological Attitudes. Elsevier; 1991:17-59. doi:10.1016/b978-0-12-590241$0.50006-x$ 